\title{
Conclusiones y Reflexiones
}

\author{
Jorge Del Río Cortina
}

"La educación es nuestro pasaporte al futuro, el mañana pertenece a las personas que se preparen hoy."

Malcolm X

Se presentaron los principales hallazgos de retos y desafíos del Departamento de Sucre a través de sus ejes económicos, tomando referencia de teorías respecto a la Competitividad y la Prospectiva, se realizaron caracterizaciones de Sectores claves, a partir de este punto, se esbozaron los retos, desafíos y estrategias necesarias para que Sucre pueda avanzar en términos Económicos y Sociales. Cabe aclarar que se han hecho muchos avances en los Sectores Económicos, sin embargo, todavía no se alcanza el máximo potencial, por lo tanto, todavía quedan muchas acciones necesarias para consolidar el territorio y llevarlo hacia una senda de crecimiento sostenible y que dedicada a la población de tal manera que esta pueda disfrutar de un Departamento, prospero, sociable y en paz.

Es importante valorar la voluntad y acción de los expertos y actores para visualizar y construir escenarios, los cuales permitan generar análisis y visión colectiva de objetivos para identificar desafíos y retos, junto con acciones y estrategias que conlleven a transformar el presente en un futuro deseable a través del mediano y largo plazo.

La Competitividad económica y empresarial, será más viable, en la medida que se acompañe de un enfoque amplio y articulado al desarrollo social e individual de las personas como agentes económicos y como sujetos sociales con ejercicio de libertades y derechos, así como promotores de solidaridad y Cooperación; lo mismo que comprometidos con el respeto a la naturaleza y sostenibilidad del planeta y la especie humana, ante los cambios ambientales cada vez más retadores que se presentan. 